\title{
Correction to: the Effects of Exposure to Mephedrone \\ During Adolescence on Brain Neurotransmission and Neurotoxicity in Adult Rats
}

\author{
Katarzyna Kamińska ${ }^{1}$ - Karolina Noworyta-Sokołowska ${ }^{1}$ - Anna Górska ${ }^{1}$ - Joanna Rzemieniec ${ }^{2}$ - Agnieszka Wnuk ${ }^{2}$. \\ Adam Wojtas $^{1} \cdot$ Grzegorz Kreiner $^{3} \cdot$ Małgorzata Kajta $^{2} \cdot$ Krystyna Gołembiowska $^{1}$
}

Published online: 23 March 2019

(C) Springer Science+Business Media, LLC, part of Springer Nature 2019

Correction to: Neurotoxicity Research (2018) 34:525-537 https://doi.org/10.1007/s12640-018-9908-0

Acknowledgments: This study was supported by the Grant No 2013/09/B/NZ7/04104 from the National Science Center (Poland).

Publisher's Note Springer Nature remains neutral with regard to jurisdictional claims in published maps and institutional affiliations.

The online version of the original article can be found at https://oi.org/ 10.1007/s12640-018-9908-0

Krystyna Gołembiowska nfgolemb@cyf-kr.edu.pl

1 Department of Pharmacology, Institute of Pharmacology, Polish Academy of Sciences, 12 Smętna, 31-343 Kraków, Poland

2 Department of Experimental Neuroendocrinology, Institute of Pharmacology, Polish Academy of Sciences, 12 Smętna, 31-343 Kraków, Poland

3 Department of Brain Biochemistry, Institute of Pharmacology, Polish Academy of Sciences, 12 Smętna, 31-343 Kraków, Poland 